\title{
Deformation of crane rail for pile supported warehouse by adjacent macadam stockyard
}

\author{
Yoshinori Iwasaki ${ }^{\text {i) }}$ and Tomohiro Masunari ${ }^{\text {ii) }}$ \\ i) Director, Geo Research Institute, 4-3-2, Itachi-bori, Osaka 550-0012, Japan \\ ii) Expert Adviser, KOKUSAI KOGYO CO., LTD., 2 Rokubancho, Chiyoda-ku, Tokyo, 102-0085, Japan
}

\begin{abstract}
A warehouse that had been built in thick sot soil ground with long PC piles of point supported and used as steel products center was divided into two parts. The western half was retained as it was with piled foundation and reused as automobile disassembly yard. The eastern half was used as macadam stock yard after dismantling ware structure as well as foundation piles. Within a few months after the operation of stockyard, the columns of the adjacent disassembly yard were found being settled. Overhead travelling cranes in the disassembly yard was also found being deformed. A question why the structure that is supported by point bearing piles should have settled was sent to the first author. This paper describes the process of geotechnical study and field monitoring including GPS to disclose the mechanism.
\end{abstract}

Keywords: pile foundation, negative friction, nearby settlement, GPS, crane rail, forensic observational method

\section{INTRODUCTION}

A warehouse for steel products constructed at reclaimed land in west Osaka in 1982 was divided into two parts in 2010. The western part was retained its original structure with overhead travelling cranes. The eastern part of the warehouse was completely dismantled with pulling the piles out. After construction of retaining wall along the boundary in December 2010, macadam stockyard began its operation in January 2011. Boundary fence was inclined and base-concrete was found cracked in mid-January 2011. In April 2011, the overhead travelling cranes became unstable due to deformation of the rails.

\section{DEFORMATION OF RAILWAYS OF OVERHEAD CRANE}

Fig.1 shows general plan view of the site, where three crane systems along $\mathrm{X} 1, \mathrm{X} 2$, and $\mathrm{X} 3$ lines. The stock yard is located adjacent to $\mathrm{X} 3$ lines with distance of a few meters. The crane rail is to be maintained within $1 / 500$ of the deformation in vertical as well as horizontal directions.

Fig.1 Plan and vertical section of overhead travelling crane with adjacent macadam stockyard

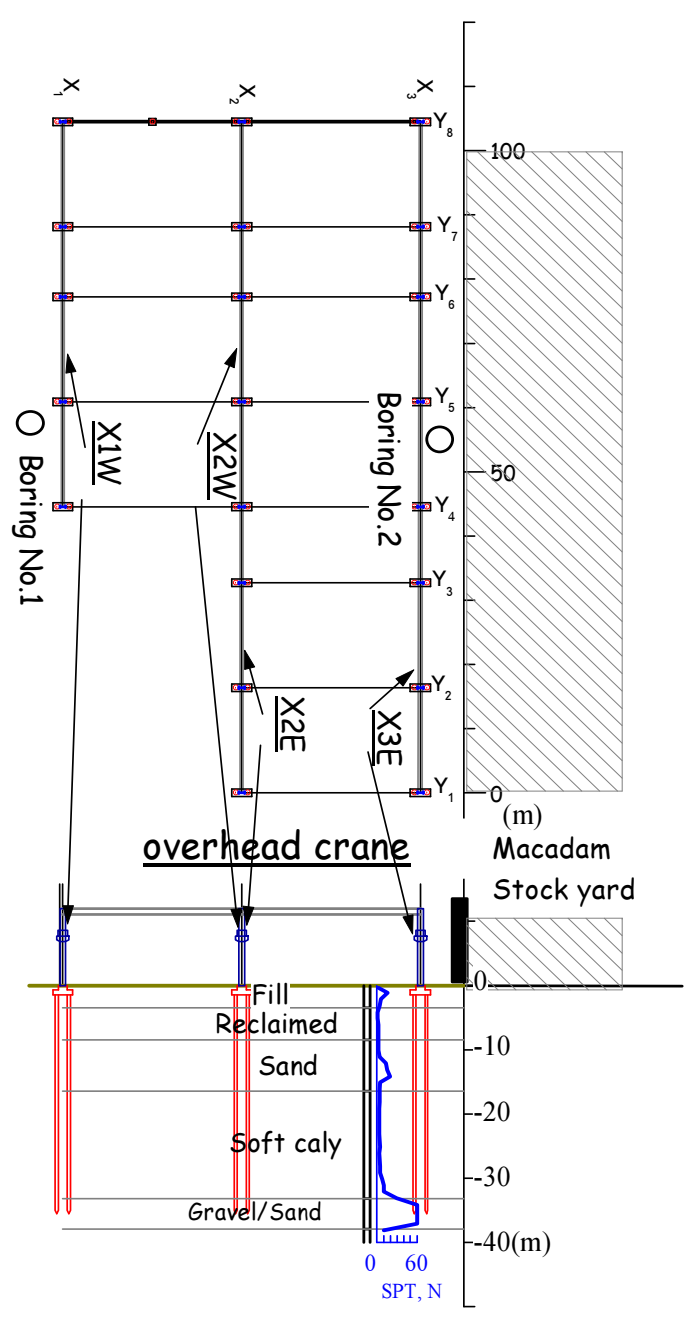


Fig.2 Settlement of

Overhead crane rail

$(2011 / 4 / 30)$

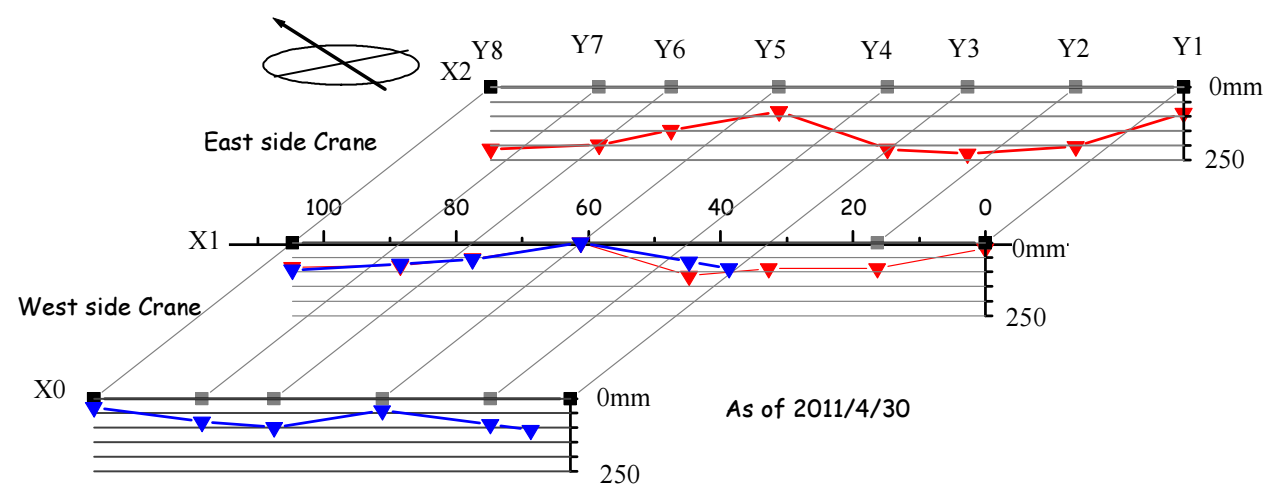

\section{GEOTECHNICAL CONDITION}

\subsection{Boring Results}

Fig.1 shows vertical section of the site with ground condition. The surface soil of the site consists of reclaimed clay, alluvial sand, and marine soft clay before the dense gravel and sand formation.Fig. 3 shows the comparison of water contents between two borings of No.1 and No.2 in Fig.1. The difference of the thickness reclaimed layer (Rc) should be noted. The thickness of Rc layer at No.2 is $3.1 \mathrm{~m}$ with $\mathrm{WC}=50 \%$, which is thinner than that at No.1 of $4.2 \mathrm{~m}$ with $60 \%$. If the water content at boring No. 2 is the same as $60 \%$, the thickness of Rc becomes $3.5 \mathrm{~m}$, which results in compression of about $0.4 \mathrm{~m}$
Boring No.1 Water Contents(\%)

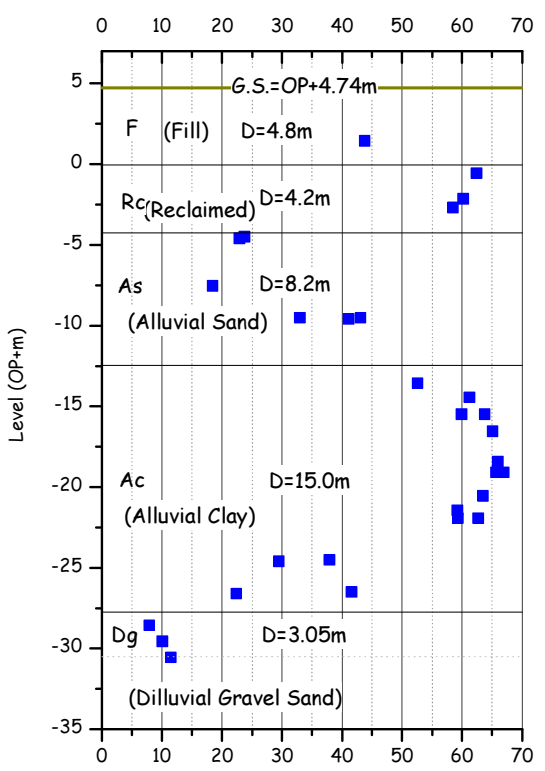

Boring No.2 Water Contents(\%)

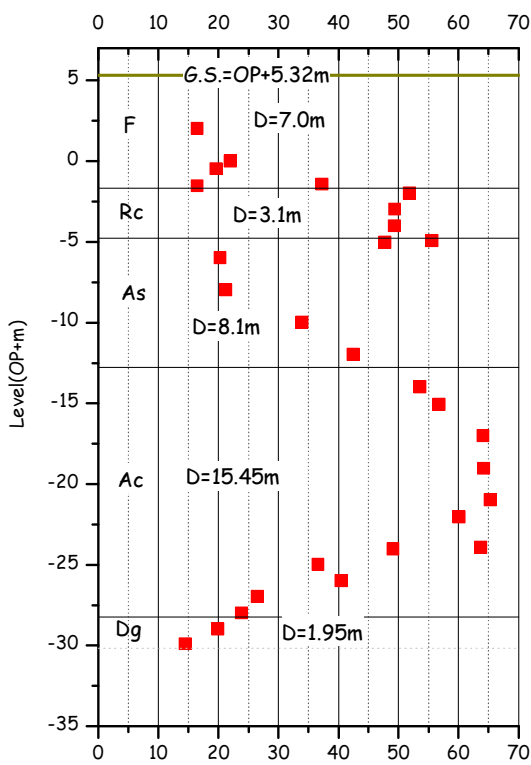

\subsection{Extensometer}

Fig.3 Comparison of Water contents ofNo1 and N0.2

Extensometers to monitor compression of each layers were installed at borings No.1 and No.2 as shown in Fig.4.
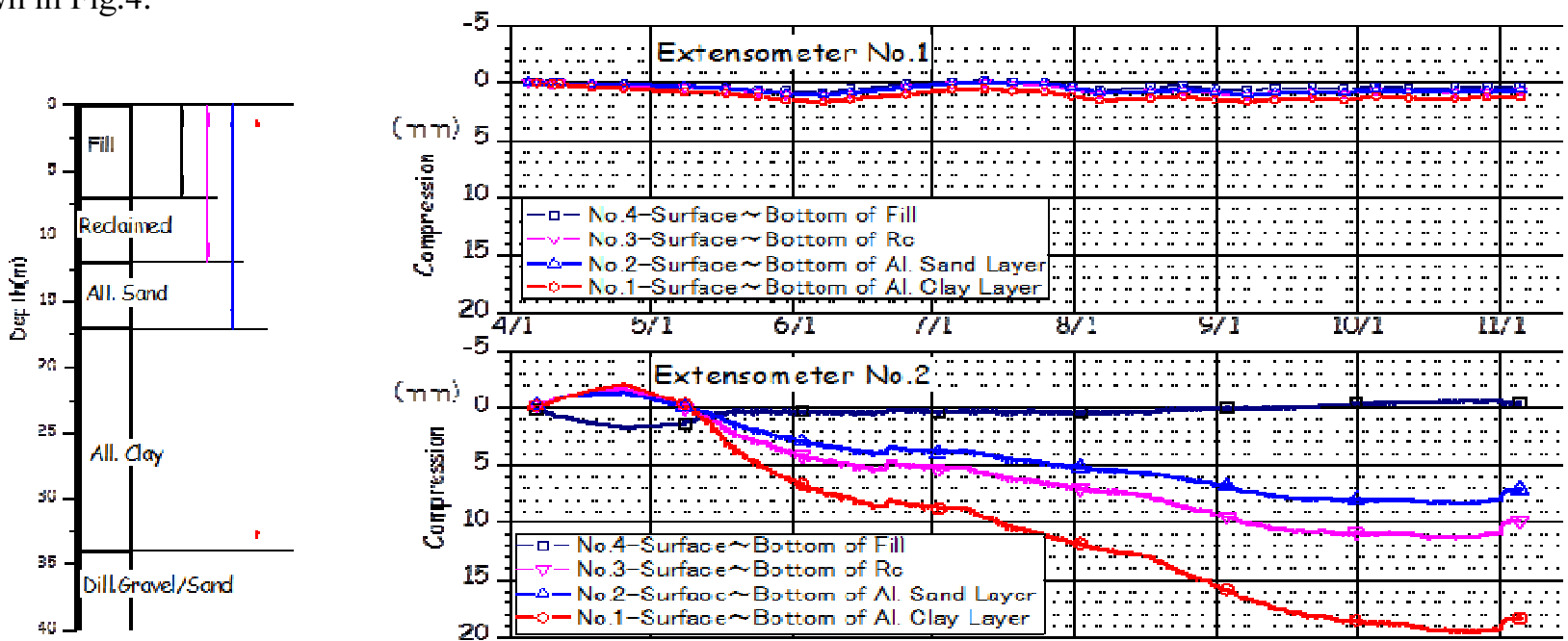

Fig.4 Installation of Extensometer

Fig. 5 Results of Extensometer 


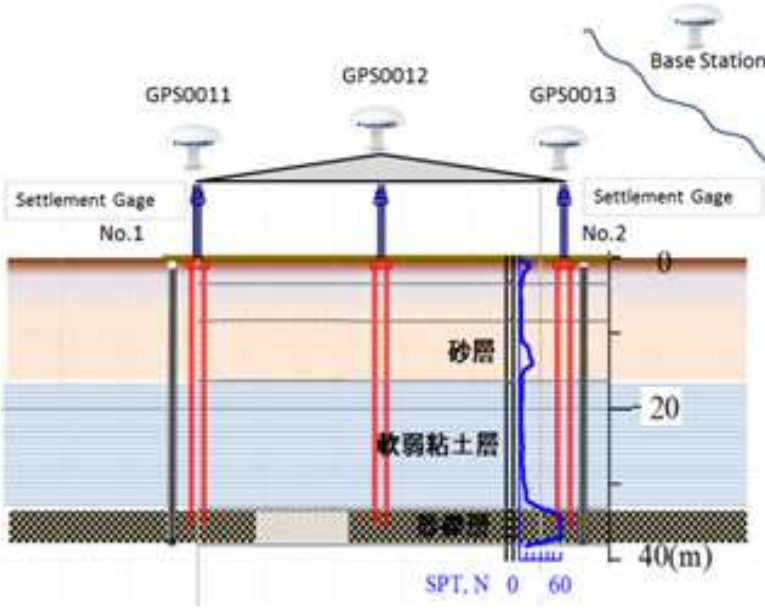

Fig.6 GPS monitoring points

\subsection{GPS monitoring}

GPS has been used for geotechnical monitoring by the authors (T.Masunari and Y.Iwasaki, 2014) in the past and GPS receivers were also installed at the three points at the top of the roof as well as another some $500 \mathrm{~m}$ away from the site as a reference base point as shown in Fig.6.

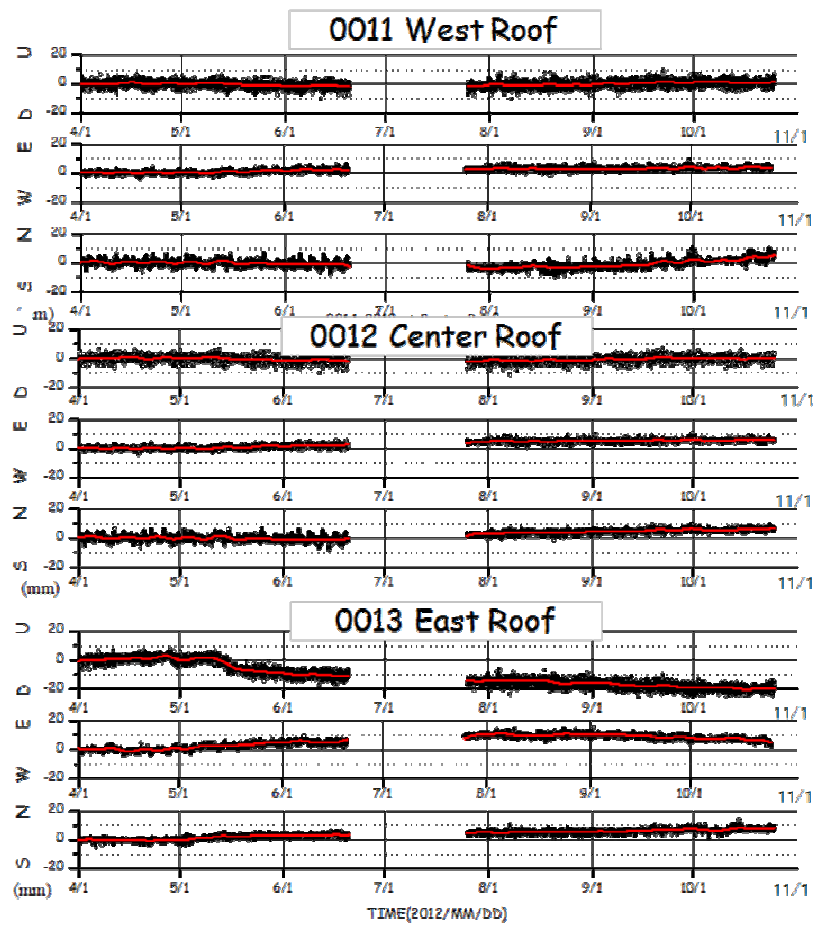

Fig.7 Results of GPS monitoring

Fig.7 shows GPS monitoring results from April 1, 2012 to November 1, 2012. Three components of NS, EW, and UD displacements in $\mathrm{mm}$ relative to the reference base station were shown. UD component at the east roof 0013 should be noted as larger settlement from in May to June. The monitoring was for six months and about $20 \mathrm{~mm}$ settlements was monitored.
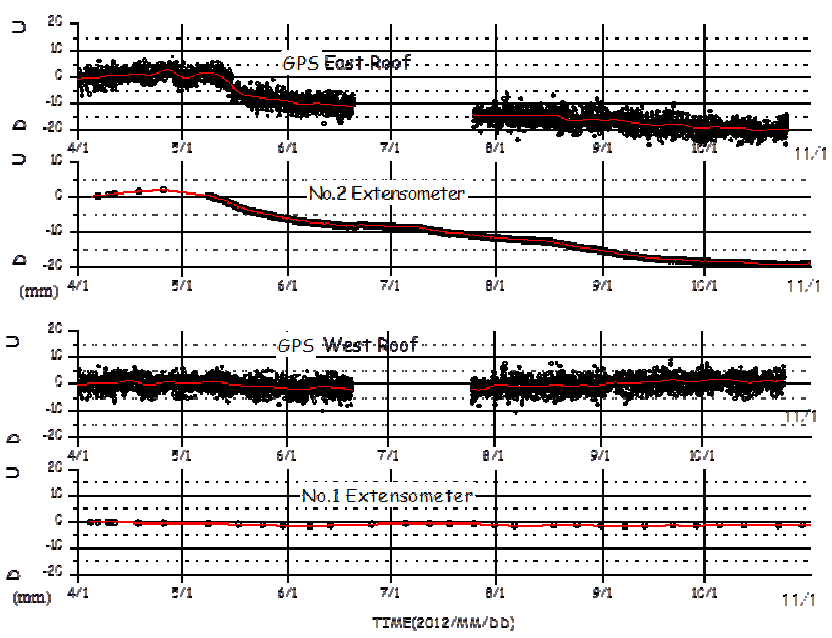

Fig.8 Comparison of extensometer and GPS

Fig. 8 compares the GPS monitored results at East roof and west roof vs. extensometers at No.2 and no1 respectively.

It is clear that the western side of the structure was settled as the same amount of the settlements of the grounds.

\section{HEIGHT OF STOCKYARD AND SETTLEMENT}

\subsection{Height of stockyard}

The macadam stockyard are always loaded or unloaded and never constant and not easy to correlate with the settlement of adjacent ground. A monitoring camera was installed to record the general view of the stockyard every 5 seconds. Based upon the recorded video, some examples are shown in Fig.9, where the site on August 10 10:00 and August 17 10:05 are shown in Fig.9

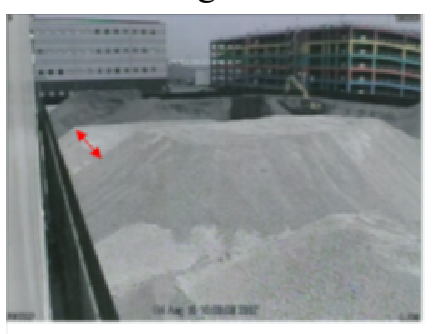

2012/8/10 10:00

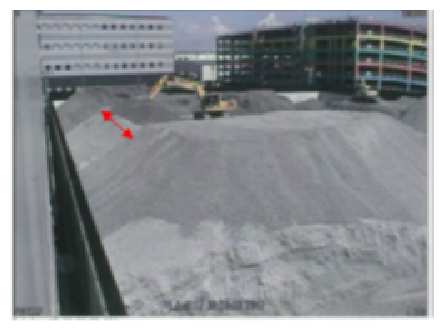

2012/8/17 10:05
Fig.9 Monitoring of Height of Macadam Stock

The arrow indicates the position where the extensometer was installed. By comparing the recorded video, the increase of the macadam height is visible and the increased level of the surface of the stock was estimated by comparison of the known size of the backhoe machine working nearby. 


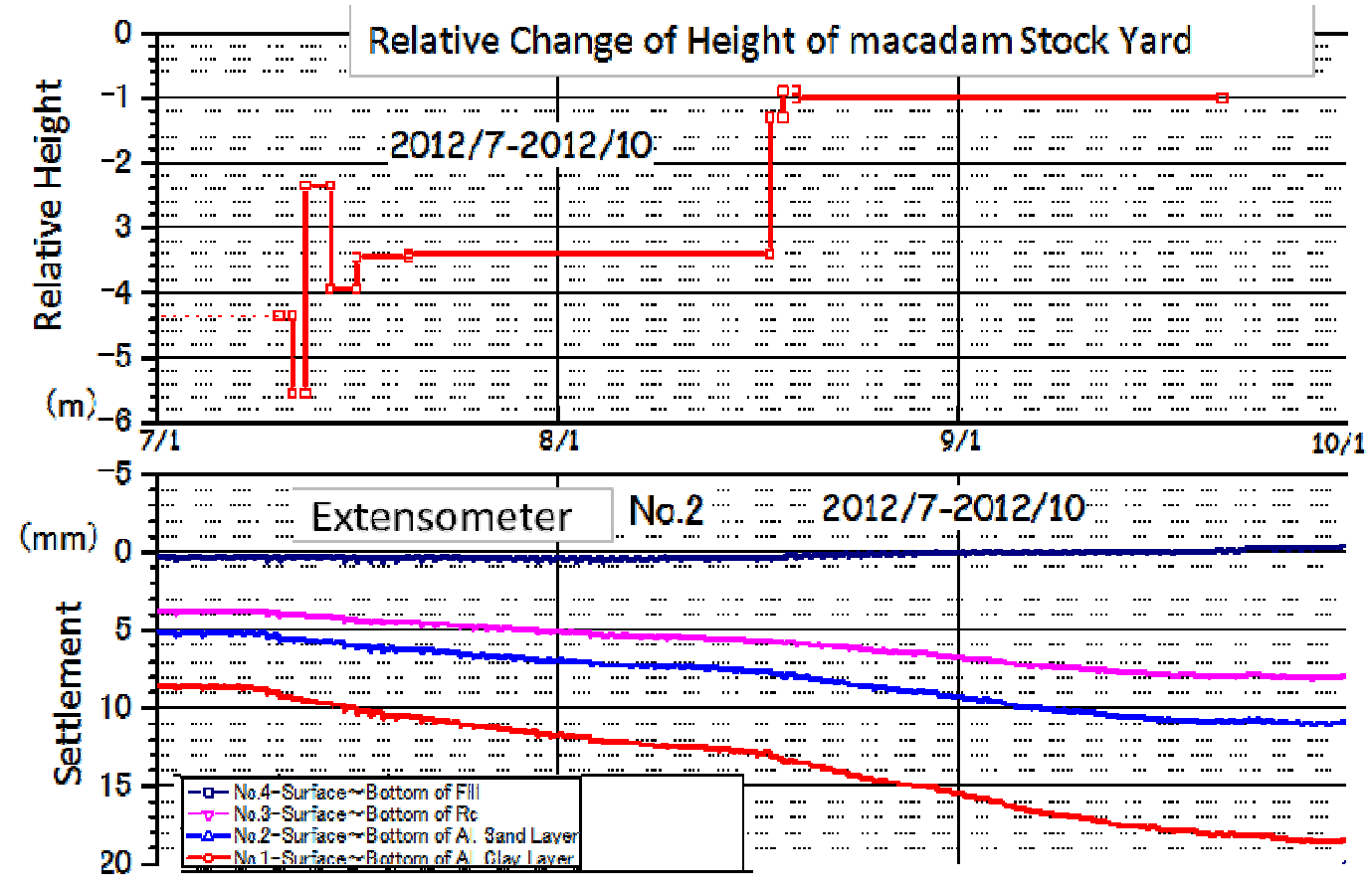

Fig.10 Comparison between the height of macadam and ground settlement

\subsection{Rate of settlement increased with increase of height of stockyard}

The monitored height of the macadam stock yard was compared with the settlement of the ground by the extensometer at Boring No.2 and shown in Fig. 10.

The monitor stated in July 10. The height of the macadam yard near the boring No.2 was analyzed and plotted in the upper part in Fig.10. The height of stock was found increased around after August 15 as shown in Fig.9 and kept constant.

The rate of the settlement is found changed at the same time of increase the height of the stockyard.

It is obvious the settlement was caused by the load of the macadam stockyard at the adjacent to the site.

\section{CONCLUSIONS}

The observational method was used to clarify the cause of the deformation of crane rail. The settlement began January 2011 under changing load of macadam stockyard. The monitoring started in April 2012 after more than 15 months when the major consolidation was considered completed. The precise monitoring by extensometer and GPS monitoring was successful to provide enough fact data to proof the cause of the settlement of the railway of overhead crane.

\section{REFERENCE}

Tomohiro Masunari and Yoshinori Iwasaki (2014) "GPS Monitoring of Displacements of Structures and Some Lessons Learnt," Proceedings of 8th Asian Rock Mechanics Symposium, ARMS8, Sapporo, Oct. 2014,pp2423-2432 